Am. J. Trop. Med. Hyg., 71(4), 2004, pp. 428-433

Copyright $@ 2004$ by The American Society of Tropical Medicine and Hygiene

\title{
A RANDOMIZED COMPARISON OF TWO ANEMIA TREATMENT REGIMENS IN TANZANIAN CHILDREN
}

\author{
DAVID SCHELLENBERG, ELIZEUS KAHIGWA, SERGI SANZ, JOHN J. APONTE, HASSAN MSHINDA, \\ PEDRO ALONSO, AND CLARA MENENDEZ \\ Centre for International Health, Institut d'Investigacions Biomedicas August Pi i Sunyer, Hospital Clinic, Villarroel, Barcelona, Spain; \\ Ifakara Health Research and Development Centre, Ifakara, Tanzania
}

\begin{abstract}
We used a prospective, open-label randomized trial to evaluate two treatment regimens in Tanzanian children two months to four years of age presenting to a hospital with a packed cell volume $(\mathrm{PCV})<25 \%$. Treatment was either standard (14 days of ferrous sulfate and an antimalarial) or extended (three months of ferrous sulfate and three antimalarial treatments). The prevalence of anemia was measured two weeks after completion of treatment and six months after recruitment. Two weeks after completing treatment, the prevalence of PCV $<33 \%$ was $58 \%$ in the standard treatment arm and $44 \%$ in the extended treatment group $(P=0.04)$, and the mean PCV was significantly higher in the extended treatment arm $(32.1 \%, \mathrm{SD}=4.5 \%$ versus $30.8 \%$, SD $=4.9 \% ; P=0.031)$. However, there was no difference in the prevalence of PCV $<25 \%$ in the first survey, and the benefits of extended therapy were only apparent six months after recruitment in children compliant with the extended treatment (odds ratio of PCV $<25 \%=$ $0.16, P=0.06)$. Compliance was satisfactory in only $39 \%$ (82 of 209) of the children in the first week of treatment. Extending the duration of therapy and improving compliance may have health benefits for anemic children in malariaendemic settings.
\end{abstract}

\section{INTRODUCTION}

More than 103 million children are anemic in Africa alone. ${ }^{1}$ The public health impact of anemia is probably highest in malaria-endemic areas, where iron deficiency also tends to be common. In southern Tanzania, the community prevalence of anemia $^{2}$ (packed cell volume $[\mathrm{PCV}]<33 \%$ ) in children less than five years old was $87 \%$ and the annual incidence of severe anemia $(\mathrm{PCV}<25 \%)$ was 0.6 episodes per infant. ${ }^{3}$ In this setting, anemia is a leading cause of pediatric admission and inpatient pediatric death, even though blood transfusions are available. Although the management of anemia is one of the most frequently encountered clinical problems in subSaharan Africa, surprisingly little information is available on the effect of frequently used treatment regimens. ${ }^{4-6}$

The etiology of anemia is frequently multi-factorial, with the relative contribution of iron deficiency, malaria, hemoglobinopathies, and intestinal parasitosis (e.g., hookworm) being different in distinct settings. In Ifakara in southern Tanzania, a recent intervention cohort study concluded that iron deficiency and malaria cause $29 \%$ and $60 \%$, respectively, of severe anemia episodes in infancy. ${ }^{3}$ Intestinal parasites and hemoglobinopathies are unlikely to be causes of anemia of public health relevance in children less than five years old in this setting. ${ }^{7,8}$ Thus, the standard approach to anemia treatment with ferrous sulfate and antimalarial seems appropriate, particularly where access to diagnostic tools is poor. Iron is often given for two weeks, which is shorter than the recommended treatment of iron deficiency anemia in standard texts, where treatment is continued for three months after the hemoglobin level has returned to normal. ${ }^{9}$ Although this approach has been encouraged "where possible" by the World Health Organization and the United Nations Childrens Fund Integrated Management of Childhood Illness (IMCI), ${ }^{10}$ the benefits remain undocumented. Thus, it is possible that many anemic children living in malarious areas receive inadequate treatment and their hemoglobin levels do not increase high into the normal range. Subsequent reinfection with malaria may depress hemoglobin levels to compromising levels that require blood transfusion, an unattractive end-result given the difficulties accessing blood transfusions, the consequences of a delay in receiving a necessary transfusion, ${ }^{11,12}$ and the increasing prevalence of human immunodeficiency virus and other infectious agents in most sub-Saharan countries.

Given the major contribution of malaria to anemia, it may be useful to extend the period of protection against Plasmodium falciparum infection beyond that afforded by a single treatment dose at the start of the anemia treatment regimen. This will increase the time available for hematologic recovery before the next $P$. falciparum insult. Furthermore, although it is now clear that prophylactic doses $(\leq 2 \mathrm{mg} / \mathrm{kg} / \mathrm{day})$ of iron do not affect risk of malaria, ${ }^{3,13-15}$ there is a suggestion of an increased risk of malaria in children receiving treatment doses of iron. ${ }^{5,16,17}$ Thus, it is prudent to cover any extended period of iron treatment with anti-malarial protection.

We report a two-arm randomized comparison of the 14-day anemia treatment versus an extended three-month regimen of iron and antimalarials.

\section{MATERIALS AND METHODS}

Study area, recruitment, and treatment assignment. The study was conducted in the semi-urban setting of Ifakara, a malaria holoendemic area of southern Tanzania described in detail elsewhere. ${ }^{3,18}$ Year round malaria transmission causes clinical cases predominantly in young children. Sulfadoxinepyrimethamine (SP) remains efficacious with no late clinical failures in a recent study. ${ }^{19}$

The study protocol was reviewed and approved by the ethical committee of the Ifakara Health Research and Development Center's and the National Medical Research Coordinating Committee of Tanzania. Sick children attending the Mother and Child Health Clinic or the pediatric ward of St. Francis Designated District Hospital were eligible if they had a PCV $<25 \%$, were between two months and five years of age, were permanent residents of the Ifakara study area, and had a parent who was able and willing to give written informed consent. Recruitment started in January 2000 and was completed in March 2001. Children were excluded if they met clinical criteria for blood transfusion (i.e., had chest indrawing indicating respiratory distress) or if they were in- 
volved in another trial. A recruitment questionnaire documented demographic characteristics and the PCV, and a thick blood film was checked for $P$. falciparum parasitemia. Each child was allocated the lowest available study number and assigned the treatment indicated on a card within an opaque envelope labeled only with the study number, thus concealing treatment allocation until assignment of the intervention. Treatments were randomly allocated to study numbers by a computer program using variable-size block randomization. The envelopes were prepared at a remote site by someone not involved in field activities.

Interventions, participant flow, and follow-up. Treatment doses were assigned on the basis of weight categories: children $<10 \mathrm{~kg}$ received a half tablet of SP (Shelys Pharmaceuticals, Dar es Salaam, Tanzania, each tablet contained $125 \mathrm{mg}$ of sulfadoxine and $6.25 \mathrm{mg}$ of pyrimethamine) and half ferrous sulfate tablets ( $30 \mathrm{mg}$ of elemental iron as ferrous sulfate; West-Coast Pharmaceutical Works, Ahmedabad, India). Children weighing $\geq 10 \mathrm{~kg}$ were given whole SP and ferrous sulfate tablets. The target dose of elemental iron was $4 \mathrm{mg} /$ $\mathrm{kg} / \mathrm{day}$. Children in the standard treatment arm were given a single dose of SP and 14 days of ferrous sulfate. Children allocated to the extended treatment were given a single dose of SP, a 28-day course of ferrous sulfate, and a date to return one month later, when they were informed that further anemia treatment would be provided. Written instructions reinforced this message. At the second visit, a second dose of SP was administered, an additional 28 days of ferrous sulfate dispensed and a third date was given, one month later. At the third visit, the final dose of SP and a third course of 28 days ferrous sulfate was given. Iron doses were packaged in ziplock plastic drug wallets with a pictorial reminder to administer one dose per day. All doses of SP were supervised.

The follow-up scheme is shown in Figure 1. Compliance with iron was assessed by pill counts when photo-identity cards were delivered one week after recruitment, when children in the extended treatment arm received doses two and three of SP, and when all children were invited for the first cross-sectional survey two weeks after completion of treat- ment. It was anticipated that compliance with extended treatment might be inadequate. To document this, children were deliberately not followed-up if they did not attend for subsequent doses of SP and iron on time because such follow-up is likely to enhance compliance. Incomplete compliance data was considered more desirable than the complete but biased data that would have resulted from more vigorous follow-up. All children were invited to the second survey six months after recruitment. At the cross-sectional surveys, the PCV, $P$. falciparum parasitemia, erythrocyte morphology, and sickle cell status were assessed. Mothers were encouraged to bring their child to a project clinical officer at the Mother and Child Health Clinic or St. Francis Designated District Hospital if the child became unwell, when clinical data were recorded on pre-coded questionnaires, thus documenting the frequency of admission, blood transfusion, episodes of malaria, and outpatient visits. Axillary temperatures were measured using electronic thermometers.

Blood slides were read according to standard quality controlled procedures. ${ }^{3}$ Briefly, each slide was read independently by two slide readers and a computer program was used to identify slides with discordant readings, which would then be read a third time. The PCVs were measured in a microcapillary tube after centrifugation and hemoglobin electrophoresis was performed on cellulose acetate strips. Microcytic hypochromic anemia was defined on the basis of erythrocyte morphology on thin blood film examination and a PCV $<33 \%$.

Data management and statistical analysis. Data were double entered and cleaned before databases were locked and the analysis conducted using Stata version 7 (Stata Corporation, College Station, TX) according to a pre-agreed analytical plan. Anemia was defined as a PCV $<33 \%$ and was considered severe when the PCV was $<25 \%$. A sample size of 150 children in each arm was estimated to provide $80 \%$ power to determine with $95 \%$ confidence a reduction of $33 \%$ in the proportion of children with anemia (Epi-Info, Centers for Disease Control and Prevention, Atlanta, GA). Children were said to be compliant if they consumed all scheduled doses of SP and at least $75 \%$ of the ferrous sulfate doses. The

\section{EXTENDED TREATMENT}

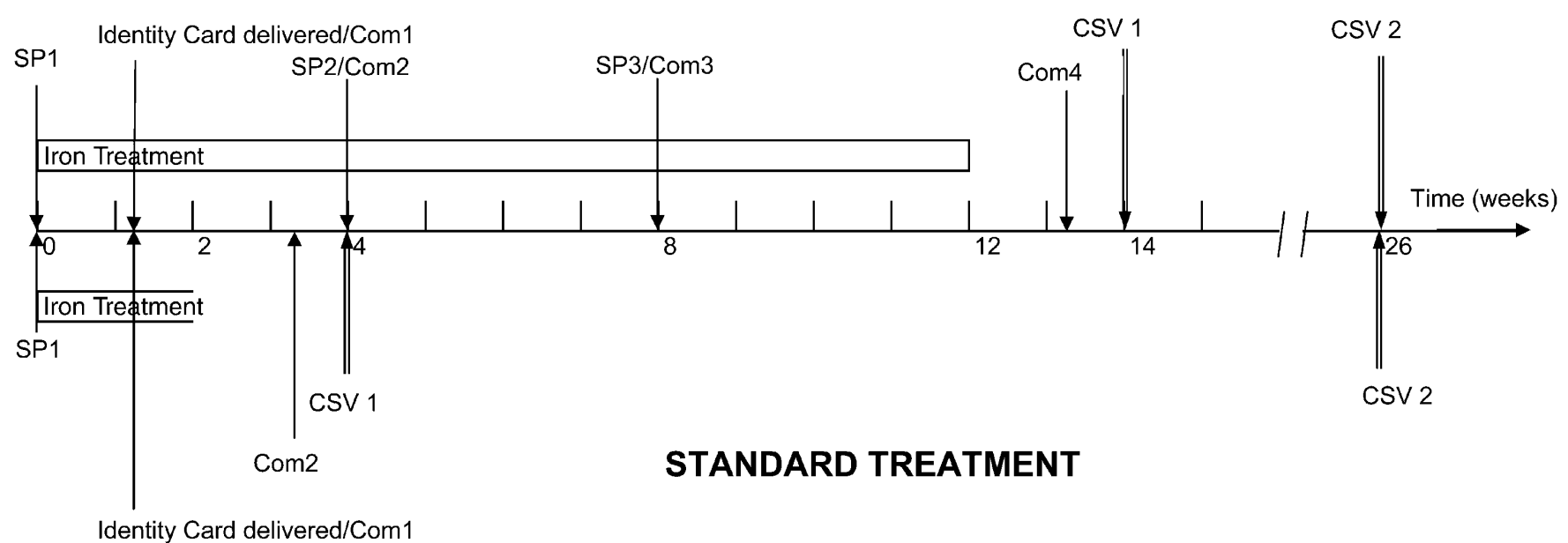

FIGURE 1. Schedule of trial events. SP = sulfadoxine-pyrimethamine treatment; Com = compliance assessment; CSV $=$ cross-sectional survey. 
primary endpoint was based on the proportion of anemic children at the first survey, regardless of compliance. The effect of the interventions on severe anemia was also assessed, and both endpoints were evaluated at the second survey. Odds ratios (ORs) were calculated using logistic regression and the protective effect defined as $(1-\mathrm{OR})$. The effect on the incidence of presentation to hospital and of blood transfusion was also evaluated. The analyses were repeated including only compliant children.

\section{RESULTS}

A total of 311 children were recruited. Completeness of follow-up was similar in the two arms (Figure 2), as was the time between recruitment and withdrawal or death. The groups were comparable at recruitment (Table 1), with a mean PCV of $21.4 \%$ (SD $=2.6)$ in the standard treatment arm and $21.5 \%(\mathrm{SD}=2.6)$ in the extended treatment arm.

Two weeks after completing anemia treatment, the prevalence of anemia was $58 \%$ in the standard treatment arm and $44 \%$ in the extended treatment group, with a significant protective effect of $42 \%$ (Table 2). Similarly, the mean PCV was higher in children receiving the extended treatment than in those receiving the standard treatment $(32.1 \%, \mathrm{SD}=4.5 \%$ versus $30.8 \%, \mathrm{SD}=4.9 \% ; P=0.031)$. The mean increase in $\mathrm{PCV}$ also tended to be higher in children receiving the extended treatment $(10.2 \%, \mathrm{SD}=5.7 \%$ versus $8.9 \%, \mathrm{SD}=$ $5.9 \% ; P=0.082)$. The two groups had a similar prevalence of severe anemia in the first survey, and only one child, in the standard treatment arm, had a PCV $<15 \%$. At the second survey, the prevalence of anemia was similar in the two groups. However, those who complied with the extended treatment tended to have less severe anemia than those compliant with the standard treatment $(P=0.06)$.

There were no differences in the incidence of attendance to outpatients, admission, blood transfusion, or clinical malaria between the two groups (Table 3). The prevalences of hypochromic, microcytic anemia and $P$. falciparum parasitemia were also similar in the two groups in both cross-sectional surveys (Table 4).

The pattern of compliance varied during the treatment course. Overall compliance, assessed two weeks after treatment should have been completed, was $87 \%$ (108 of 124) in the standard treatment arm. In the extended arm, 55\% (85 of $154)$ of the children received two or more doses of SP, and $44 \%$ (68 of 154) received all three doses. All children who received three doses of SP and who also had complete compliance data $(n=39)$ had good overall compliance to iron. One week after treatment started, compliance was satisfactory in only 39\% (82 of 209) of the children: $22 \%$ (47 of 209) were poor compliers and $38 \%$ (80 of 209) had over-consumed iron, and $12 \%$ (26 of 209) were taking more than twice the expected dose. Over-consumption was particularly marked in the extended treatment arm in which a week after the start of treatment, $21 \%$ (22 of 103) had consumed at least twice the expected amount of iron and 2\% (2 of 103) had consumed more than four times the expected amount of iron.

\section{DISCUSSION}

We conducted a randomized trial comparing a standard 14-day anemia treatment with an extended, three-month regi-

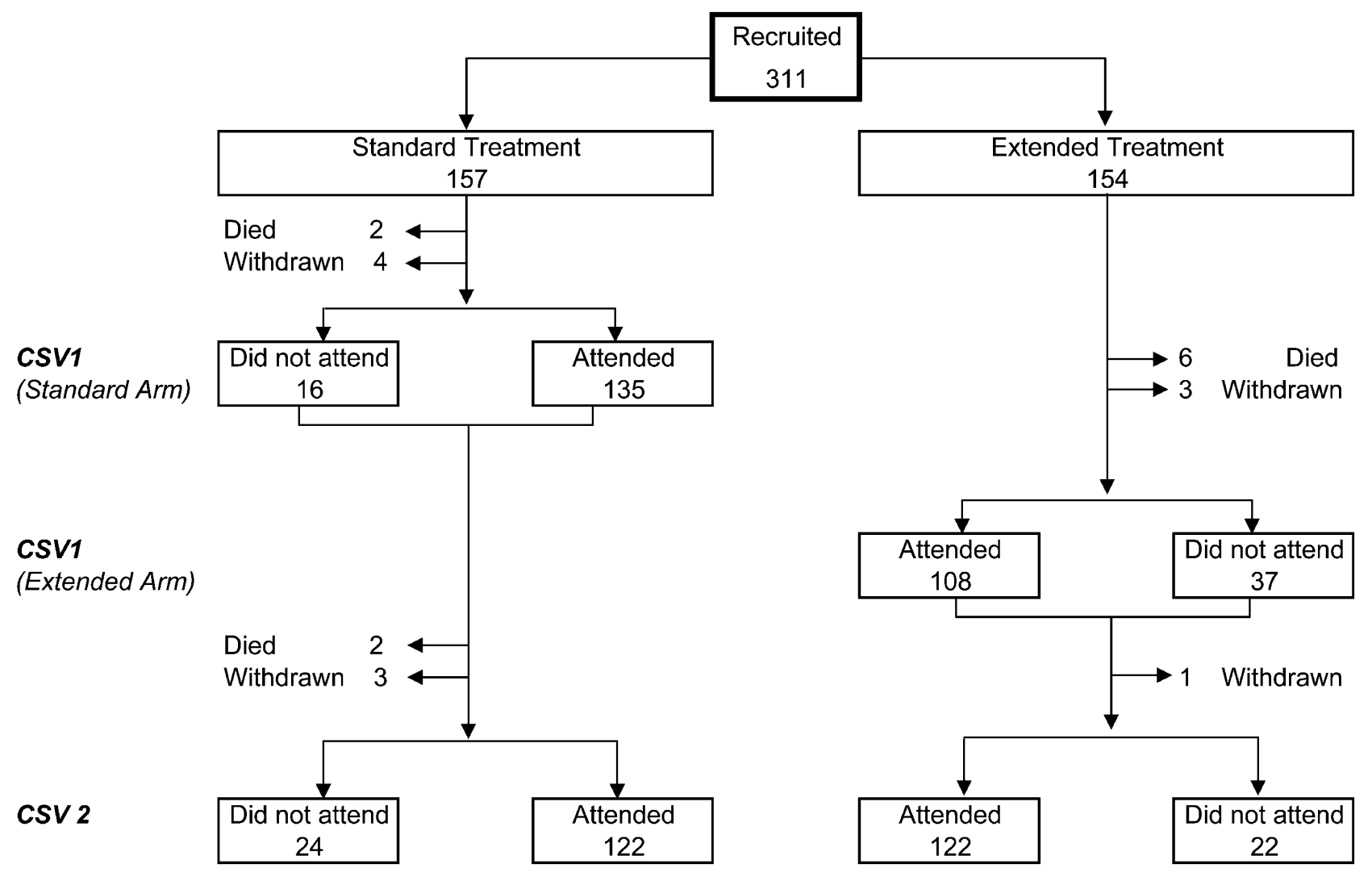

FIGURE 2. Trial profile. CSV $=$ cross-sectional survey. 
TABLE 1

Baseline comparability*

\begin{tabular}{|c|c|c|c|c|c|}
\hline \multirow[b]{3}{*}{ Variable } & & \multicolumn{4}{|c|}{ Treatment group } \\
\hline & & \multicolumn{2}{|c|}{ Standard } & \multicolumn{2}{|c|}{ Extended } \\
\hline & & $\mathrm{n} / \mathrm{N}$ & $\%$ & $\mathrm{n} / \mathrm{N}$ & $\%$ \\
\hline Male sex & & $82 / 157$ & 52 & $73 / 154$ & 47 \\
\hline \multirow{3}{*}{$\begin{array}{l}\text { Age category, } \\
\text { months }\end{array}$} & $2-12$ & $41 / 157$ & 26 & $35 / 154$ & 23 \\
\hline & $13-24$ & $44 / 157$ & 28 & $40 / 154$ & 26 \\
\hline & $25-60$ & $72 / 157$ & 46 & $79 / 154$ & 51 \\
\hline \multirow[t]{4}{*}{ Malnutrition } & None & $73 / 155$ & 47 & $74 / 152$ & 49 \\
\hline & Mild & $62 / 155$ & 40 & $58 / 152$ & 38 \\
\hline & Moderate & $17 / 155$ & 11 & $16 / 152$ & 11 \\
\hline & Severe & $3 / 155$ & 2 & $4 / 152$ & 3 \\
\hline \multirow{3}{*}{$\begin{array}{l}\text { Distance }(\mathrm{km}) \\
\text { home-SFDDH }\end{array}$} & $0-1.59$ & $56 / 157$ & 36 & $52 / 154$ & 34 \\
\hline & $1.6-3.09$ & $52 / 157$ & 33 & $47 / 154$ & 31 \\
\hline & $\geq 3.1$ & $49 / 157$ & 31 & $55 / 154$ & 36 \\
\hline Blood slide positivity & & $107 / 151$ & 71 & $95 / 146$ & 65 \\
\hline $\begin{array}{l}\text { Mosquito net use } \\
\text { (CSV1) }\end{array}$ & & $96 / 137$ & 70 & $77 / 105$ & 73 \\
\hline \multirow[t]{5}{*}{ Hemoglobin trait } & $\mathrm{AA}$ & $114 / 150$ & 76 & $118 / 149$ & 79 \\
\hline & $\mathrm{AF}$ & $19 / 150$ & 13 & $18 / 149$ & 12 \\
\hline & AS & $9 / 150$ & 6 & $10 / 149$ & 7 \\
\hline & FS & $3 / 150$ & 2 & 1/149 & 1 \\
\hline & SS & $5 / 150$ & 3 & 2/149 & 1 \\
\hline \multirow{3}{*}{$\begin{array}{l}\text { Iron compliance } \\
\text { after } 1 \text { week }\end{array}$} & $<75 \%$ & 29/106 & 27 & $18 / 103$ & 17 \\
\hline & $75-125 \%$ & 43/106 & 41 & $39 / 103$ & 38 \\
\hline & $>125 \% \dagger$ & $34 / 106$ & 32 & $46 / 103$ & 45 \\
\hline
\end{tabular}

men. The prevalence of severe anemia in the standard treatment arm decreased from $100 \%$ at recruitment to $10 \%$ two weeks after completing treatment, and this effect was maintained six months after recruitment. However, at least half the children receiving the standard treatment remained anemic in each survey. In the extended treatment arm, $44 \%$ of the children were anemic shortly after completing treatment, which is equivalent to a $42 \%$ protective effect compared with the standard regimen. Although this benefit may have been partly due to the increased time available for children in the extended treatment arm for recovery from acute, malariainduced anemia, rather than an enhanced efficacy of the drug regimen, this would not have been the case in the second survey. Some analyses, in particular those confined to good compliers, were based on small numbers and many of the endpoints failed to reach statistical significance. Nevertheless, children in the extended arm were less anemic at both crosssectional surveys, with confidence intervals for the various effect estimates overlapping each other. In particular, children compliant with the extended regimen were $84 \%$ less likely $(P=0.06)$ to have severe anemia six months after the initial diagnosis. Taken together, these findings are consistent with a favorable effect of the extended treatment, although this regimen still produced results that were far from satisfactory.

The importance of $P$. falciparum infection in the pathogenesis of anemia in this setting is underlined by the $68 \%$ prevalence of parasitemia at recruitment, which is much higher than that found in other cohorts from the same area. ${ }^{18,20}$ Many of the children recruited may have had a PCV slightly more than $25 \%$ before their $P$. falciparum infection and became severely anemic as an acute result of their parasitization. This might tempt some to stop treating anemic children with iron in such settings. ${ }^{21}$ However, this ignores the difficulties of distinguishing anemia due to malaria from that due to iron-deficiency, especially in resource-poor settings. The implications of not adequately treating an anemic child in a malaria-endemic setting are potentially grave, whereas iron treatment is relatively safe. Furthermore, there is clear evidence of a benefit of treating children with severe malarial anemia with iron, ${ }^{4}$ although this should be done in conjunction with antimalarial treatment. ${ }^{5}$

There are major gaps in the evidence base for anemia treatment in African children. First, what should be the PCV threshold for treatment? Children recruited to this study had a PCV $<25 \%$, which is similar to the $27 \%$ cut-off adopted by the IMCI. ${ }^{10}$ Why the threshold for treatment in Africa is set lower than in the west is not clear, especially since anemic children living in malaria-endemic settings are presumably at higher risk of serious illness or death than anemic children in non-endemic settings. However, the accurate assessment of the burden of anemia is complicated by technical and ethical concerns. Second, we were able to find only one randomized study of iron and antimalarial use in the treatment of anemia ${ }^{6}$, which questions the basis for the treatment recommendations for this very common problem.

Assessments of compliance with iron were based on tablet counts and may therefore be inaccurate if tablets were not

TABLE 2

Effect of standard and extended anemia treatment regimens*

\begin{tabular}{|c|c|c|c|c|c|c|c|}
\hline \multirow[b]{3}{*}{ Analysis } & \multicolumn{4}{|c|}{ Treatment arm } & \multirow[b]{3}{*}{ OR } & \multirow[b]{3}{*}{$95 \% \mathrm{CI}$} & \multirow[b]{3}{*}{ Protective effect } \\
\hline & \multicolumn{2}{|c|}{ Standard } & \multicolumn{2}{|c|}{ Extended } & & & \\
\hline & $\mathrm{n} / \mathrm{N}$ & $\%$ & $\mathrm{n} / \mathrm{N}$ & $\%$ & & & \\
\hline \multicolumn{8}{|l|}{ All recruited children } \\
\hline PCV $<33 \%$ survey 1 & $78 / 135$ & 57.8 & $48 / 108$ & 44.4 & 0.58 & $(0.35-0.97)$ & $42 \% \dagger$ \\
\hline $\mathrm{PCV}<25 \%$ survey 1 & $14 / 135$ & 10.4 & $8 / 108$ & 7.4 & 0.69 & $(0.29-1.68)$ & $31 \%$ \\
\hline $\mathrm{PCV}<33 \%$ survey 2 & $61 / 122$ & 50.0 & $62 / 122$ & 50.8 & 1.03 & $(0.63-1.70)$ & $-3 \%$ \\
\hline PCV $<25 \%$ survey 2 & $12 / 122$ & 9.8 & $7 / 122$ & 5.7 & 0.55 & $(0.21-1.40)$ & $45 \%$ \\
\hline \multicolumn{8}{|l|}{ Compliant children } \\
\hline PCV $<33 \%$ survey 1 & $40 / 67$ & 59.7 & $17 / 39$ & 43.6 & 0.52 & $(0.24-1.15)$ & $48 \%$ \\
\hline $\mathrm{PCV}<25 \%$ survey 1 & $7 / 67$ & 10.5 & $3 / 39$ & 7.7 & 0.71 & $(0.19-2.72)$ & $29 \%$ \\
\hline $\mathrm{PCV}<33 \%$ survey 2 & $37 / 65$ & 56.9 & $17 / 37$ & 46.0 & 0.64 & $(0.29-1.44)$ & $36 \%$ \\
\hline $\mathrm{PCV}<25 \%$ survey 2 & $9 / 65$ & 13.9 & $1 / 37$ & 2.6 & 0.16 & $(0.00-1.06)$ & $84 \% \neq$ \\
\hline
\end{tabular}

$* \mathrm{OR}=$ odds ratio; $\mathrm{CI}=$ confidence interval; $\mathrm{PCV}=$ packed cell volume.

$\dagger P=0.04$
$\dagger P=0.06$ 
TABLE 3

Effect of different anemia treatment regimens on the incidence of outpatient department (OPD) attendance, admission, blood transfusion and clinical malaria*

\begin{tabular}{|c|c|c|c|c|c|c|}
\hline \multirow[b]{2}{*}{ Endpoint } & \multicolumn{3}{|c|}{ Standard } & \multicolumn{3}{|c|}{ Extended } \\
\hline & Cases & $\begin{array}{l}\text { Time at risk } \\
\text { (years) }\end{array}$ & Rate & Cases & $\begin{array}{l}\text { Time at risk } \\
\text { (years) }\end{array}$ & Rate \\
\hline Admission & 23 & 75.3 & 0.31 & 28 & 74.8 & 0.37 \\
\hline OPD visits & 236 & 61.3 & 3.85 & 214 & 61.6 & 3.47 \\
\hline Blood transfusion & 1 & 75.2 & 0.01 & 3 & 76.5 & 0.04 \\
\hline Clinical malaria $\dagger$ & 10 & 75.9 & 0.13 & 8 & 74.7 & 0.11 \\
\hline
\end{tabular}

consumed by the intended recipient but either wasted or taken by someone else. However, more stringent approaches to the assessment of compliance are fraught with difficulties because all biochemical markers of iron status are affected by acute infections, including $P$. falciparum. ${ }^{22-24}$ According to our compliance assessments, over-consumption of iron may become a cause for concern. The risk of toxicity increases as the dose of elemental iron increases: doses more than $30 \mathrm{mg} /$ $\mathrm{kg}$ are potentially toxic and doses in excess of $180 \mathrm{mg} / \mathrm{kg}$ are potentially fatal. ${ }^{25}$ Our target dose of elemental iron was 4 $\mathrm{mg} / \mathrm{kg} / \mathrm{day}$. Thus, a 7.5- or $>45$-fold over-consumption would be required to fall into the potentially toxic and potentially fatal categories, respectively. It seems unlikely that any of the children over-consuming iron in our study would have experienced serious adverse effects as a result. Nevertheless, the smallest child recruited weighed $4.1 \mathrm{~kg}$; had she been randomized to the extended treatment arm and consumed the entire 28-day course at once, she would have received the equivalent of $185 \mathrm{mg} / \mathrm{kg}$, a dangerous overdose.

Compliance was poor despite the fact that the drugs were dispensed with clear instructions to sick children in a trial setting. Less than half the children in the extended treatment arm received all intended doses of SP. The trial was deliberately conducted so that the likelihood of altered compliance, simply by virtue of being in the trial, was minimized. Thus, the patterns of compliance documented are likely to reflect those

TABLE 4

Effect of standard and extended anemia treatment regimens on prevalence of microcytic hypochromic anaemia and Plasmodium falciparum parasitemia*

\begin{tabular}{|c|c|c|c|c|}
\hline \multirow[b]{2}{*}{ Analysis } & \multicolumn{2}{|c|}{$\begin{array}{l}\text { Standard } \\
\text { treatment }\end{array}$} & \multicolumn{2}{|c|}{$\begin{array}{l}\text { Extended } \\
\text { treatment }\end{array}$} \\
\hline & $\mathrm{n} / \mathrm{N}$ & $\%$ & $\mathrm{n} / \mathrm{N}$ & $\%$ \\
\hline \multicolumn{5}{|l|}{ Intention to treat analyses } \\
\hline \multicolumn{5}{|l|}{ Survey 1} \\
\hline Hypochromic microcytic anemia & $5 / 131$ & 3.8 & 3/104 & 2.9 \\
\hline$P$ falciparum positive & $14 / 135$ & 10.4 & $14 / 104$ & 13.5 \\
\hline \multicolumn{5}{|l|}{ Survey 2} \\
\hline Hypochromic microcytic anemia & $1 / 122$ & 0.8 & $2 / 122$ & 1.6 \\
\hline P. falciparum positive & $24 / 122$ & 19.7 & $19 / 122$ & 15.6 \\
\hline \multicolumn{5}{|l|}{ Compliant children } \\
\hline \multicolumn{5}{|l|}{ Survey 1} \\
\hline Hypochromic microcytic anemia & $1 / 64$ & 1.6 & $0 / 37$ & 0.0 \\
\hline$P$ falciparum positive & $8 / 67$ & 11.9 & $3 / 37$ & 8.1 \\
\hline \multicolumn{5}{|l|}{ Survey 2} \\
\hline Hypochromic microcytic anemia & $1 / 65$ & 1.5 & $1 / 37$ & 2.7 \\
\hline$P$. falciparum positive & $14 / 65$ & 21.5 & $4 / 37$ & 10.8 \\
\hline
\end{tabular}

in real life and as such give cause for concern. Various strategies to improve compliance have been explored. Some have focused on changing the formulation of iron to try and reduce the incidence of side effects, which are thought to contribute to poor compliance. ${ }^{26,27}$ Other factors known to affect compliance include the motivation of those dispensing the drug, its perceived safety and efficacy, its presentation, and the complexity of the dosing regimen. ${ }^{28-32}$ Finally, although hitherto unproven, it seems likely that inviting patients to return for a follow-up appointment, as recommended by the IMCI, ${ }^{10}$ might also improve compliance.

In conclusion, health benefits are likely to result from improved compliance to anemia and other treatments in children living in malaria-endemic settings. Extending the period of antimalarial and iron treatment of anemic children in Ifakara improved outcome: even though compliance was poor, the effects in those who complied were marked. This study does not provide definitive information to guide policy makers, but underlines the need for further work on this important topic. It would be useful to establish a rational threshold for anemia treatment, to assess the efficacy of alternative anemia treatment regimens, and to develop ways of improving compliance to treatment, and thus to establish an evidence-base for practical anemia treatment in Africa.

Received May 28, 2003. Accepted for publication March 29, 2004.

Acknowledgments: We are grateful to the mothers and children recruited into the study for their co-operation. We also thank the nursing staff at St. Francis Designated District Hospital and the Ifakara Mother and Child Health Clinic for facilitating patient flow to the study team. The trial was supported by Dr. Fred Lwilla (Kilombero District Medical Officer) and Dr. Patience Kibatala (Medical Director, St. Francis Designated District Hospital). Field activities were supervised by Morsad Nywage, data management by Chris Msokame, laboratory procedures by John Wigayi, and clinical activities by Athmani Malende.

Financial support: This investigation received financial support from the United Nations Development Program/World Bank/World Health Organization Special Program for Research and Training in Tropical Diseases.

Authors' addresses: David Schellenberg, Centre for International Health, Institut d'Investigacions Biomedicas August Pi i Sunyer, Hospital Clinic, Villarroel 170, Barcelona 08036, Spain and Ifakara Health Research and Development Centre, PO Box 53, Ifakara, Tanzania, Telephone: 44-1296-681-160, Fax: 44-1296-681-099, E-mail: dmschellenberg@aol.com. Elizeus Kahigwa and Hassan Mshinda, Ifakara Health Research and Development Centre, PO Box 53, Ifakara, Tanzania. Sergi Sanz, John Aponte, Pedro Alonso, and Clara Menendez, Centre for International Health, Institut d'Investigacions Biomedicas August Pi i Sunyer, Hospital Clinic, Villarroel 170, Barcelona 08036, Spain.

Reprint requests: Clara Menendez, Centre for International Health, Institut d'Investigacions Biomedicas August Pi i Sunyer, Hospital Clinic, Villarroel 170, Barcelona 08036, Spain.

\section{REFERENCES}

1. de Maeyer E, Adiels-Tegman M, 1985. The prevalence of anemia in the world. World Health Stat Q 38: 302-316.

2. Schellenberg D, Schellenberg JR, Mushi A, de Savigny D, Mgalula L, Mbuya C, Victora CG, 2003. The silent burden of anaemia in Tanzanian children: a community-based study. Bull World Health Organ 81: 581-590.

3. Menendez C, Kahigwa E, Hirt R, Vounatsou P, Aponte J, Font F, Acosta C, Schellenberg D, Galindo C, Kimario J, Urassa H, Brabin B, Smith T, Kitua A, Tanner M, Alonso P, 1997. Randomised placebo controlled trial of iron supplementation and 
malaria chemoprophylaxis for prevention of severe anaemia and malaria in Tanzanian infants. Lancet 350: 844-850.

4. Bojang KA, Palmer A, Hensbroek MB, Banya WA, Greenwood BM, 1997. Management of severe malarial anemia in Gambian children. Trans R Soc Trop Med Hyg. 91: 557-561.

5. Smith AW, Hendrickse RG, Harrison C, Hayes RJ, Greenwood BM, 1989. The effects on malaria of treatment of irondeficiency anemia with oral iron in Gambian children. Ann Trop Paediatr 9: 17-23.

6. Desai MR, Mei JV, Kariuki SK, Wannemuehler KA, PhillipsHoward PA, Nahlen BL, Kager PA, Vulule JM, ter Kuile FO, 2003. Randomized, controlled trial of daily iron supplementation and intermittent sulfadoxine-pyrimethamine for the treatment of mild childhood anemia in western Kenya. $J$ Infect Dis. 187: 658-666.

7. Gascon J, Vargas M, Schellenberg D, Urassa H, Casals C, Kahigwa E, Aponte J, Mshinda H, Vila J, 2000. Diarrhea in children under 5 years of age from Ifakara, Tanzania: a case control study. J Clin Microbiol 38: 4459-4462.

8. Clegg JB, Weatherall DJ, 1999. Thalassemia and malaria: new insights into an old problem. Proc Assoc Am Physicians 111: 278-282.

9. Pippard MJ, 1987. Iron deficiency and overload. Weatherall D, Ledingham J, Warrell D, eds. Oxford Textbook of Medicine. Second edition. Oxford University Press, Oxford, 86.

10. WHO/CAH, UNICEF, 2000. Handbook Integrated Management of Childhood Illness. Geneva: World Health Organization. 50 and 131.

11. Lacritz E, Campbell C, Ruebush T, Hightower A, Wakube W, Steketee R, Were J, 1992. Effect of blood transfusion on survival among children in a Kenyan hospital. Lancet 340: 524 528.

12. English M, Ahmed M, Ngando C, Berkley J, Ross A, 2002. Blood transfusion for severe anemia in children in a Kenyan hospital. Lancet 359: 494-495.

13. Harvey PW, Heywood PF, Nesheim MC, Galme K, Zegans M, Habicht JP, Stephenson LS, Radimer KL, Brabin B, Forsyth $\mathrm{K}$, 1989. The effect of iron therapy on malarial infection in Papua New Guinean schoolchildren. Am J Trop Med Hyg 40: 12-18.

14. Berger J, Dyck JL, Galan P, Aplogan A, Schneider D, Traissac P, Hercberg S, 2000. Effect of daily iron supplementation on iron status, cell-mediated immunity, and incidence of infections in 6-36 month old Togolese children. Eur J Clin Nutr 54: 29-35.

15. Verhoef H, West CE, Nzyuko SM, de Vogel S, van der Valk R, Wanga MA, Kuijsten A, Veenemans J, Kok FJ, 2002. Intermittent administration of iron and sulfadoxine-pyrimethamine to control anaemia in Kenyan children: a randomised controlled trial. Lancet 360: 908-914.

16. Murray MJ, Murray AB, Murray MB, Murray CJ, 1978. The adverse effect of iron repletion on the course of certain infections. BMJ 2: 1113-1115.

17. Oppenheimer SJ, Gibson FD, Macfarlane SB, Moody JB, Harrison C, Spencer A, Bunari O, 1986. Iron supplementation increases prevalence and effects of malaria: report on clinical studies in Papua New Guinea. Trans R Soc Trop Med Hyg 80: 603-612.

18. Schellenberg D, Aponte JJ, Kahigwa E, Mshinda H, Tanner M, Menendez C, Alonso PL, 2004. The incidence in children of clinical malaria detected by active case detection in Ifakara, southern Tanzania. Trans R Soc Trop Med Hyg 97: 387-394.

19. Schellenberg D, Kahigwa E, Drakeley C, Malende A, Wigayi J, Msokame C, Aponte JJ, Tanner M, Mshinda H, Menendez C, Alonso PL, 2002. The safety and efficacy of sufadoxinepyrimethamine, amodiaquine, and their combination in the treatment of uncomplicated Plasmodium falciparum malaria. Am J Trop Med Hyg 67: 17-23.

20. Schellenberg D, Menendez C, Kahigwa E, Aponte J, Vidal J, Tanner M, Mshinda H, Alonso P, 2001. Intermittent treatment for malaria and anaemia control at time of routine vaccinations in Tanzanian infants: a randomised, placebo-controlled trial. Lancet 357: 1471-1477.

21. van den Hombergh J, Dalderop E, Smit Y, 1996. Does iron therapy benefit children with severe malaria-associated anemia? A clinical trial with 12 weeks supplementation of oral iron in young children from Turiani Division, Tanzania. J Trop Pediatr 42: 220-227.

22. Ayatse J, Ekanem E, 1994. Plasmodium falciparum malaria: its effects on some haematological parameters in normal and sickle cell Nigerian children. Trop Med Parasitol 45: 219-222.

23. Das BS, Thurnam D, Das DB, 1997. Influence of malaria on markers of iron status in children: implications for interpreting iron status in malaria-endemic communities. Br J Nutr 78: 751760.

24. Menendez C, Quinto LL, Kahigwa E, Alvarez L, Ferbnandez R, Gimenez N, Schellenberg D, Aponte JJ, Tanner M, Alosno P, 2001. Effect of malaria on soluble transferrin receptor levels in Tanzanian infants. Am J Trop Med Hyg 65: 138-142.

25. Reynolds J, 1996. Iron. J Reynolds, ed. Martindale: The Extra Pharmacopoeia. Thirty-first edition. Royal Pharmaceutical Society, London, 1366-1367.

26. Zlotkin S, Arthur P, Antwi K, Yeung G, 2001. Treatment of anemia with microencapsulated ferrous sulfate plus ascorbic acid supplied as sprinkles to complementary (weaning) foods. Am J Clin Nutr 74: 791-795.

27. Ekstrom E-C, Kavishe F, Habicht J-P, Frongillo E, Rasmussen K, Hemed L, 1996. Adherence to iron supplementation during pregnancy in Tanzania; determinants and hematologic consequences. Am J Clin Nutr 64: 368-374.

28. Allen S, Snow R, Menon A, Greenwood B, 1990. Compliance with malaria chemoprophylaxis over a five-year period among children in a rural area of The Gambia. J Trop Med Hyg 93: 313-322.

29. Massawe S, Urassa E, Lindmark G, Nystrom L, 1995. Anemia in pregnancy; perceptions of patients in Dar es Salaam. East Afr Med J 72: 498-503.

30. Ansah E, Gyapong J, Agyepong I, Evans D, 2001. Improving adherence to malaria treatment for children: the use of prepacked chloroquine tablets vs. chloroquine syrup. Trop Med Int Health 6: 496-504.

31. Okonkwo P, Akpala C, Okafor H, Mbah A, Nwaiwu O, 2001. Compliance to correct dose of chloroquine in uncomplicated malaria correlates with improvement in the condition of rural Nigerian children. Trans $R$ Soc Trop Med 95: 320-324.

32. Djimde A, Plowe C, Diop S, Dicko A, Wellems T, Doumbo O, 1998. Use of antimalarial drugs in Mali; policy versus reality. Am J Trop Med Hyg 59: 376-379. 